University of Nebraska - Lincoln

DigitalCommons@University of Nebraska - Lincoln

U.S. Environmental Protection Agency Papers

U.S. Environmental Protection Agency

2011

\title{
Web-Based Automated Remediation Performance Monitoring and Visualization of Contaminant Mass Flux and Discharge
}

Mark L. Kram

Groundswell Technologies, Inc.

Steve Airhart

Freestone Environmental Services, Inc.

Daniel Tyler

Freestone Environmental Services, Inc.

Amy Dindal

Battelle

Andrew Barton

Battelle

See next page for additional authors

Follow this and additional works at: https://digitalcommons.unl.edu/usepapapers

Kram, Mark L.; Airhart, Steve; Tyler, Daniel; Dindal, Amy; Barton, Andrew; McKernan, John L.; and Gustafson, Gregg, "Web-Based Automated Remediation Performance Monitoring and Visualization of Contaminant Mass Flux and Discharge" (2011). U.S. Environmental Protection Agency Papers. 141. https://digitalcommons.unl.edu/usepapapers/141

This Article is brought to you for free and open access by the U.S. Environmental Protection Agency at DigitalCommons@University of Nebraska - Lincoln. It has been accepted for inclusion in U.S. Environmental Protection Agency Papers by an authorized administrator of DigitalCommons@University of Nebraska - Lincoln. 


\section{Authors}

Mark L. Kram, Steve Airhart, Daniel Tyler, Amy Dindal, Andrew Barton, John L. McKernan, and Gregg Gustafson 


\section{Web-Based Automated Remediation Performance Monitoring and Visualization of Contaminant Mass Flux and Discharge}

Mark L. Kram

Steve Airhart

Daniel Tyler

Amy Dindal

Andrew Barton

John L. McKernan

Gregg Gustafson

Environmental monitoring, data processing, and reporting methods are expensive, labor- and resource-intensive, time-consuming, and often inaccurate. An innovative project management platform was developed for integrating environmental monitoring sensors, telemetry, geographical information systems, models, and geostatistical algorithms for automatically generating contour maps and time-stamped renderings of sensor attributes and multivariate analyses. More specifically, algorithms converting sensor-derived head and solute concentration values allow for automated monitoring of mass flux and discharge to evaluate groundwater remediation system performance and contaminant discharges from aquifers to surface-water receptors. Life-cycle costs and carbon footprints were reduced due to the elimination of energy and labor expenditures associated with transportation, data collection, laboratory efforts, report generation, and information dissemination. A brief summary of two demonstrations of this sensor-based water resources management application is presented. (C) 2011 Wiley Periodicals, Inc.

\section{INTRODUCTION}

Groundwater monitoring methods are expensive, labor- and resource-intensive, and time-consuming, and can often be inaccurate due to sampling, handling, and transport considerations. Understanding of solute transport during remediation efforts and in mixing zones between groundwater and surface-water bodies poses several challenges due to hydraulic and geologic complexities, and because of dynamics that are rarely monitored in a continuous manner sufficient to understand mass movement. The authors performed several pilot-scale demonstrations of an automated sensor-based project management platform for real-time continuous data collection, visualization, hydraulic and contaminant analyses, and data archiving. The software component, named Waiora, was developed to be a multimedia data acquisition, management, and visualization tool for use in environmental, water resources, oceanographic, and security applications. Waiora has the ability to monitor sensors measuring hydraulic head and solute concentrations through a web interface. In addition, Waiora includes many unique processing features that are 
While the primary purpose of the project was to evaluate the nitrate sensor performance, nitrate mass discharge was monitored at high frequency intervals in the bioreactor for over nine consecutive weeks. essential for understanding transport and mass discharge in a geospatial and temporal context.

A pilot demonstration was performed in an agricultural tile drainage field located in Iowa as part of a US EPA Environmental Technology Verification (ETV) project, where nitrate sensors were being evaluated in a subsurface trench filled with bioreactive materials used to break down nitrate-laden influent at a US Department of Agriculture (USDA) site located in Ames, Iowa (US EPA, 2010). Wells and sensors for monitoring head and solute concentrations were installed during the bioreactor construction.

Nitrate-laden waste from agricultural runoff was introduced into the bioreactor inlet while hydraulics and concentrations were monitored. While the primary purpose of the project was to evaluate the nitrate sensor performance, nitrate mass discharge was monitored at high frequency intervals in the bioreactor for over nine consecutive weeks. Sensors measured continuous nitrate concentrations and head in 15-minute intervals from seven locations within the bioreactor. Sensors were deployed in the inlet, and in four two-inch polyvinylchloride (PVC) monitoring wells. Two sensors were deployed in one of the wells at varying depths to evaluate vertical gradients within the test cell. Data used to track sensor and remediation performance were available to key project representatives located in various parts of the country.

Specific objectives established for the US EPA ETV pilot demonstration included:

- Interface to a sensor network designed to collect continuous head and dissolved nitrate data from six monitoring wells installed within a constructed bioreactor.

- Demonstrate the utility of the web-based geospatial processing platform as a means to produce:

- customized trend plots;

- 2-D and 3-D head and concentration distributions and temporal trends;

- head distributions coupled with known hydraulic conductivity (K) distributions to estimate velocity and flow direction distributions and trends;

- velocity distributions coupled with nitrate solute concentration data to produce mass flux distributions and mass discharge through user-selected source control planes; and

- time-stamped playback loops of the geospatial changes in potentiometric head, groundwater flow directions, contaminant concentration, velocity, and mass flux and discharge distributions for bioreactor remediation performance evaluation.

A second pilot demonstration was performed at a US Department of Energy (US DOE) facility with known historical contaminant releases and ongoing remediation efforts adjacent to the Columbia River in Hanford, Washington (US DOE, 2010). The selected site was ideal for the demonstration because an automated data-collection network has been deployed, operational large-scale pump-and-treat groundwater remediation systems are in operation, and the site contains a well-defined hexavalent chromium contaminant plume resulting from historical releases. The period of performance for the demonstration was June 22, 2010, through September 30, 2010. This demonstration of on-demand, web-based hydrogeologic management applications was focused on long-term automated contaminant plume monitoring, flux-based remediation 
performance monitoring, evaluation of groundwater and surface-water interactions, upload of several years of historical data, and model validation.

A tremendous amount of groundwater data is generated at the selected DOE facility each year to support site characterization and monitoring, development of remedial alternatives and design, and optimization of remediation system performance. These data are integral to developing an accurate understanding of site conditions for facilitating project planning, prioritization of work, allocation of funds and technical resources, and timely decision making. As remediation schedules are expedited, the need to quickly and reliably assimilate, process, view, report, and archive the data is becoming increasingly important. Also, as groundwater pump-and-treat operations increase, the deployment of down-well sensors and telemetry equipment for monitoring remediation performance and the influence on the groundwater and riparian environments has become more prevalent. These automated data-collection systems generate large quantities of data on a continuous basis. Due to the immense amount of information, management of this data has become a labor-intensive endeavor. Fulfillment of data requests includes sending out unprocessed tabular files, which then require manual processing via desktop software packages, then conference and consensus before any decisions can be made. In order to live up to the full potential represented by sensor-based monitoring technologies, there exists a need for a nimble, customizable web-based project management platform that can be used by project scientists and engineers, their clients, and the regulatory community to rapidly reach consensus, calibrate models, optimize remediation efforts, and effectively document cause-and-effect responses to specific field activities.

The overall objective of the DOE pilot effort was to demonstrate the utility of an automated web-based project management platform that enables evaluation of groundwater elevation and groundwater contaminant distributions on an operable unit (OU) scale. Waiora was integrated with data collected with both manual and automated methods. Once this pilot project has been determined to be successful at the OU level, the platform could be used to centrally manage several OUs across the facility, and to streamline the data management, assessment, model optimization, and archiving processes.

Specific objectives established for the DOE pilot demonstration included:

- Interface to existing sensor network comprised of 46 wells collecting continuous head data from two separate OUs.

- Demonstrate the utility of the web-based geospatial processing platform as a means to produce:

- customized trend plots;

- 2-D and 3-D head and concentration distributions and temporal trends;

- head distributions coupled with known hydraulic conductivity (K) distributions to estimate velocity and flow direction distributions and trends;

- velocity distributions coupled with historical hexavalent chromium concentration data to produce mass flux distributions and mass discharge through user-selected source control planes located in the hyporheic zone;

- time-stamped playback loops of the geospatial changes in potentiometric head, groundwater flow directions, contaminant concentration, velocity, and mass flux and discharge distributions;
The overall objective of the DOE pilot effort was to demonstrate the utility of an automated web-based project management platform that enables evaluation of groundwater elevation and groundwater contaminant distributions on an operable unit (OU) scale. 


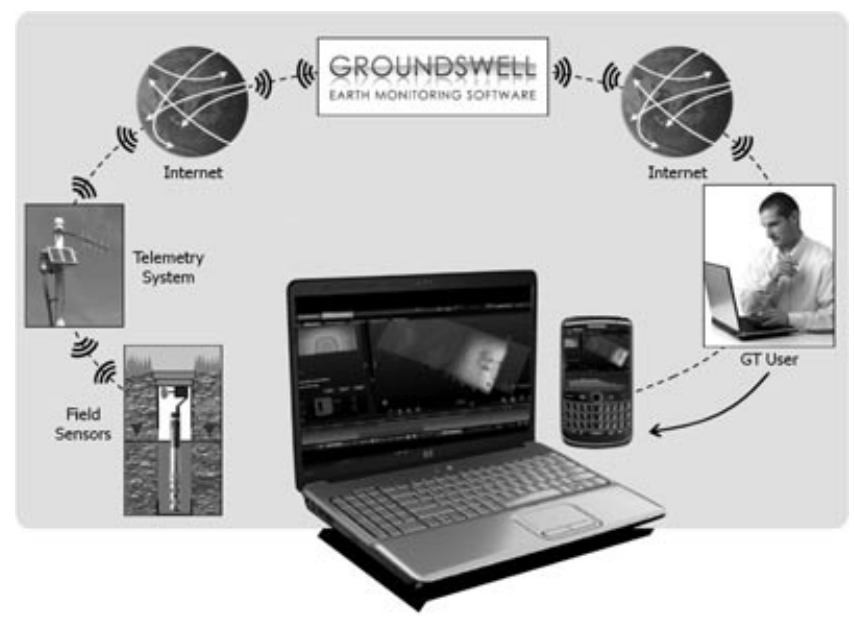

Exhibit 1. Waiora data flow from sensor to end-user

- increased understanding of interactions between groundwater and surface water via automated flux distribution determination, visualizations, and discharge estimates; and

- generation and export of interpolation layers for use in model calibration efforts.

\section{MATERIALS AND METHODS}

\section{Waiora Platform}

Waiora is a monitoring-, reporting-, and consensus-based analysis platform that integrates sensors, telemetry, geographical information systems, and automated processing and visualization capabilities to produce real-time geostatistically rendered contour diagrams and multivariate analytical output (Kram et al., 2005, 2010). Recent integration with cloud-based Internet technologies allows for robust, scalable, on-demand reporting and project management (Exhibit 1). For the two demonstrations described, Waiora was integrated with field sensors monitoring solute and water-level data in a groundwater remediation performance monitoring context. These demonstrations focused on contaminant mass flux as a means of improving groundwater remediation decisions by characterizing 3-D distributions of mass movement and tracking changes in discharge through source control planes over time (ITRC, 2010; Kram et al., 2008; Suthersan et al., 2010). While Waiora can be used with a variety of sensors, including the nitrate sensor deployed for the US EPA ETV project, the US DOE pilot project focused on conventional solute hexavalent chromium concentration data and water-level sensor data for deriving groundwater hydraulic and contaminant distributions.

Waiora is composed of a modular configuration that is designed to function similar to traditional desktop software packages. Modules, tabs, tools, time series, contouring, contouring with time series, 2-D and 3-D playback loops, transect "slicing," statistical controls, model calibration, and document repository with sharing capabilities are featured in this automated monitoring, data management, and analysis platform. Throughout the Waiora platform, images and tabular results can be exported for use in reports and presentations. High-resolution graphic format options include shapefile, .png, 
.jpg, and .csv for tabular data. Image-capture software can also be used if other formats are desired. Thresholds can be integrated to trigger notification based on regulatory exceedances and operational constraints required for controllers.

Waiora mass flux calculations are similar to those described by Kram et al. (2008) and ITRC (2010). For instance, Darcy velocity is based on co-located hydraulic conductivity and hydraulic gradient, where the gradient is determined via finite difference analyses of scalar head distributions. Mass flux at any location is determined by multiplying velocity and concentration, with results in mass per time per area. When displayed in 2-D and 3-D, mass flux distributions allow practitioners to determine where zones of mobile mass exist, and to therefore optimize remediation strategies through surgical removal or hydraulic isolation. Transect slices through 3-D mass flux distribution renderings and oriented perpendicular to flow serve as source control planes representing discharge in units of mass per time. When monitored over time, results can be used as a metric for remediation performance as well as cumulative mass discharge estimates for interactions between groundwater and surface-water bodies.

Waiora processes historical data obtained from site databases as well as real-time data obtained through sensors and telemetry. When integrated with live sensor networks, much of the manual effort currently expended on data collection, report graphics generation, and information dissemination becomes automated, continuous, and seamlessly integrated into project management protocol. Since Waiora is entirely web-based, no software downloads are required, and all data are accessible through a password-protected on-demand configuration from anywhere with an Internet connection.

\section{Sensor Networks}

The sensor network used for the US EPA ETV project was composed of seven nitrate sensors and seven water-level sensors (developed by Instrumentation Northwest [INW], Kirkland, Washington) installed within an area trenched and filled with bioreactive materials for treating the nitrate-laden influent (Exhibit 2). The nitrate sensors are

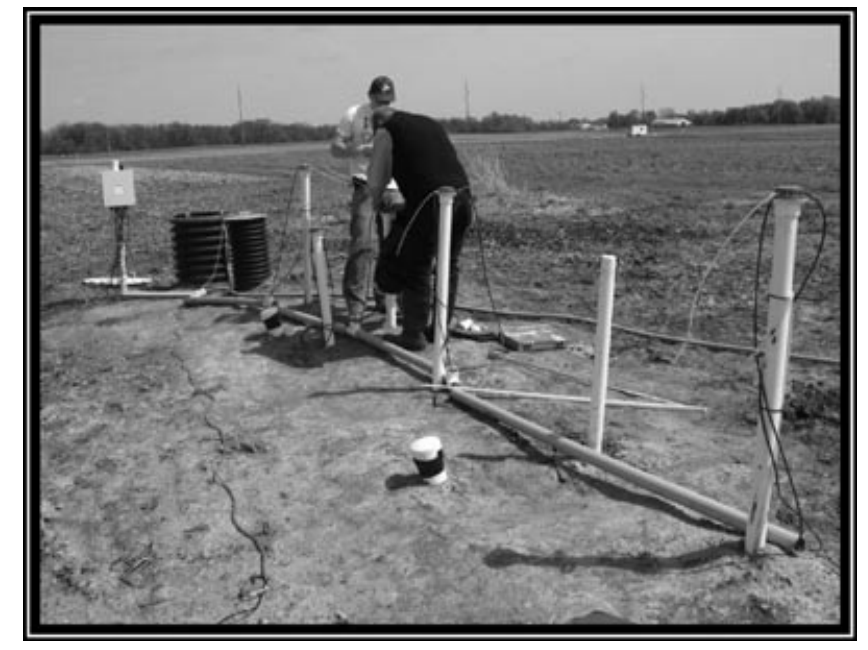

Exhibit 2. Sensor deployment in bioreactor cell (courtesy of Battelle, 2010). 
A key missing component of most currently deployed automated sensor networks is a robust software system that minimizes the time required for data processing, includes builtin quality control flags, and allows for near-realtime analysis and graphical output. composed of ion selective electrodes, while the water-level sensors include customized pressure transducers integrated with temperature and barometric corrections. Data loggers and telemetry were integrated and nitrate concentration and hydraulic head data were collected at 15-minute intervals.

The US DOE pilot demonstration focused on 46 existing monitoring wells representing a subset of the well network currently existing at two selected OUs. These data are collected in support of the pump-and-treat operations and groundwater monitoring efforts. The wells are instrumented with pressure transducers, data loggers, and telemetry equipment to automatically record and transmit real-time hydraulic head data collected on an hourly basis. Manual depth-to-water measurements are taken periodically to convert sensor-based head readings to water-elevation data. These measurements are also used as field checks to assure data quality.

Automated monitoring systems are typically composed of three main components: a remote sensor station for collection and logging of the desired data, a telemetry system that facilitates remote data retrieval, and a centralized receiving point for assembling and loading data into a database. Data collected from the automated water-level network are currently manually processed using standard spreadsheet algorithms and uploaded into a central database. This process can require up to a month or more before automatically collected data can be available for query by project staff. The queried data are used for a variety of purposes, including technical analysis, graphics production, and reporting.

A key missing component of most currently deployed automated sensor networks is a robust software system that minimizes the time required for data processing, includes built-in quality control flags, and allows for near-real-time analysis and graphical output. The subject pilot demonstrations were designed to test the ability of the Waiora software to meet these requirements in concert with commercialized sensor networks in a web-based data management environment.

\section{Data Acquisition and Management System}

Waiora serves as a sensor-neutral platform and is designed to poll either directly from the sensors or from an intermediary data portal at desired frequencies. Raw sensor data files generated from the sensor networks are typically sent to an ftp site residing on the Internet where they become accessible via a sensor portal and Waiora available through the Groundswell web site. For the US EPA project, INW's AquaPlus software served as the interface between the sensors and the ftp site. Data are automatically retrieved at a preset frequency from the ftp site and placed within the sensor portal for rapid viewing of the raw data (e.g., within seconds of data transfer), flagging via threshold and search and control commands, and archiving for future review. These files are also automatically normalized for instant automated upload into the Waiora Platform database, where they become available to the end-user for performing the analytical and visualization tasks offered by Waiora. For instance, as new sensor data are automatically uploaded to the Waiora database, the end-user gains new time steps that can be selected for performing time-series analyses, playback loops, and generating reports. The entire data acquisition and management system is maintained within a cloud computing framework, affording streamlined flexibility and stability under variable data loads in an on-demand context. The Waiora cloud-based platform can be used to manage multiple sites simultaneously 
and to perform consensus-based analyses among collaborating users working in remote locations as recommended by Triad advocates (ITRC, 2007).

\section{RESULTS AND DISCUSSION}

The US EPA project successfully demonstrated that real-time hydraulic and nitrate sensor data can be automatically uploaded, displayed, and analyzed using the web-based platform. High-frequency data-collection events proceeded while nitrate-laden agricultural runoff was routed through the bioreactor. While the key component of the ETV effort included evaluation of the nitrate sensor performance, this is beyond the scope of this discussion and will be addressed in the EPA report (Barton et al., 2011).

Exhibits 3 and 4 display automatically interpolated spatial distributions of head and nitrate channels, respectively, for a selected horizontal slice through the bioreactor at a time-stamped event during the monitoring campaign. Time-series graphs are displayed for selected sensors. Note that nitrate-laden materials were routed through Well 1 (bioreactor inlet), and nitrate was tracked over time as it propagated through the bioreactor.

Contours were derived using an inverse distance-weighted Shepard power function set at two, without anisotropy considerations. Users can control and modify interpolation settings. Since hydraulic conductivity values for the bioreactor materials are known, velocity and flux algorithms are also automatically processed using dynamic head and solute concentrations combined with static hydraulic conductivity distributions. Mobile mass distributions (depicted as interpolated mass flux values) can be viewed in 3-D, then user-selected slices can serve as control planes through which mass discharge estimates are tracked for every time step. Exhibit 5 shows a 3-D rendering of flux distribution, a source control plane oriented perpendicular to flow, and provides an estimate of mass discharge through this plane over time, represented by a histogram along the base of the window.

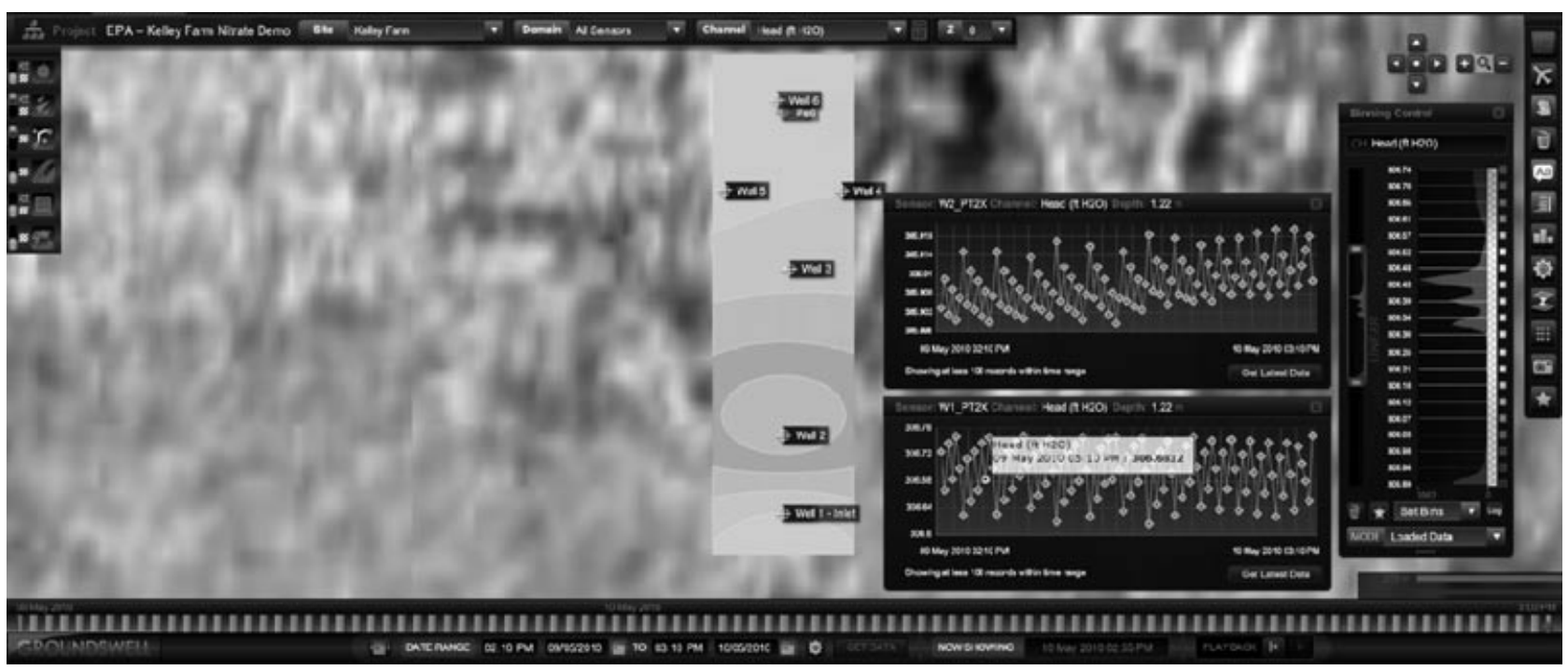

Exhibit 3. Head distributions and selected sensor time-series charts, US EPA demonstration 


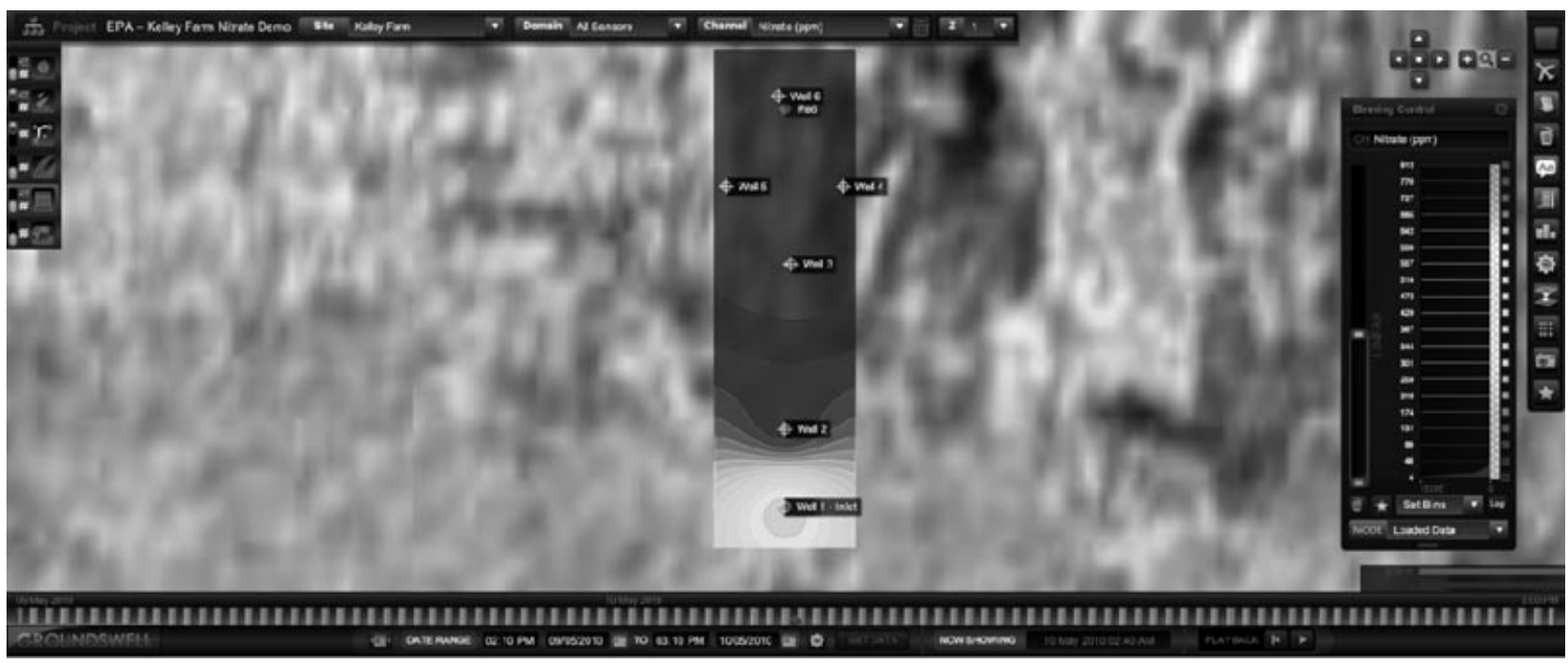

Exhibit 4. Nitrate concentration distribution, US EPA demonstration

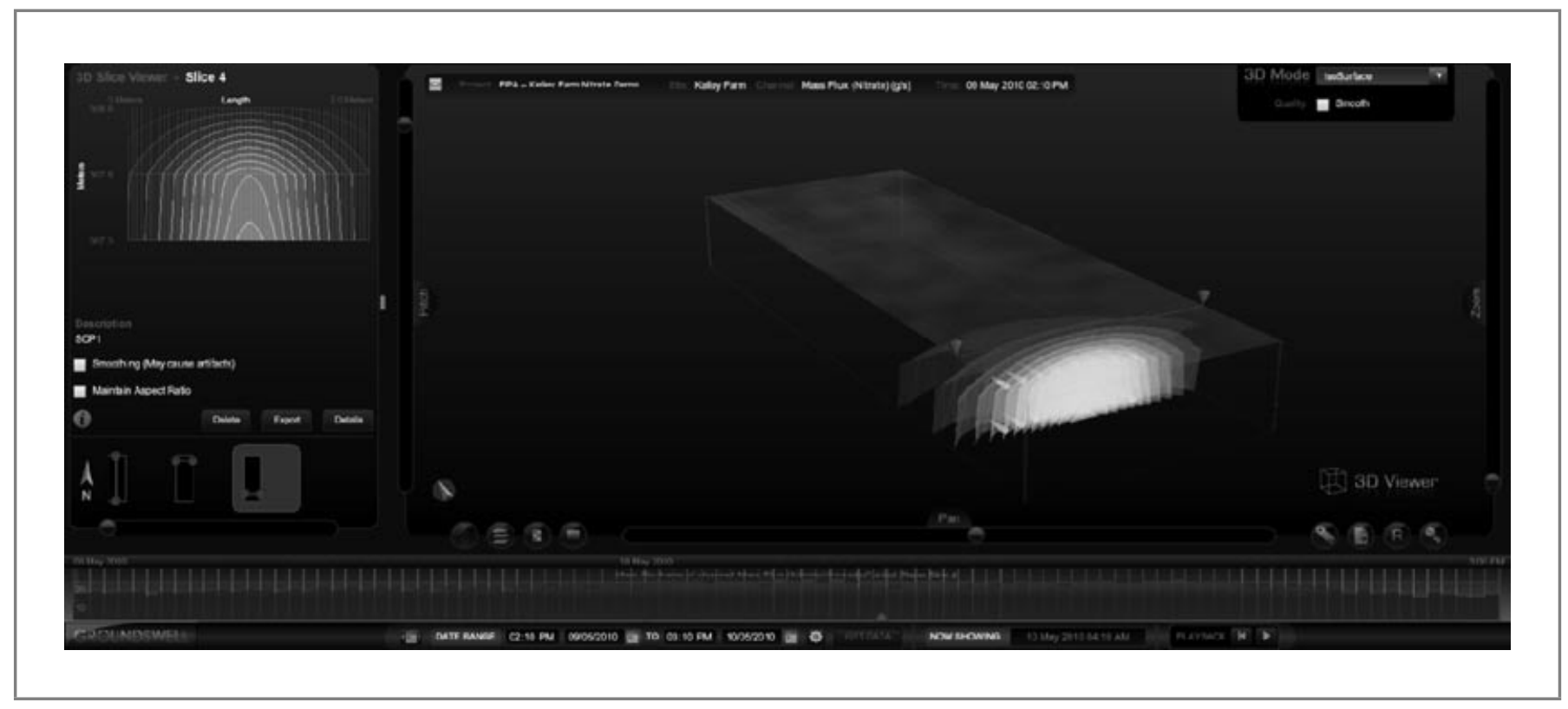

Exhibit 5. Nitrate mass discharge through source control plane, US EPA demonstration

These types of renderings can be used to design remediation systems (e.g., surgical source removal or hydraulic isolation) and to evaluate remediation performance (e.g., percent reduction in source strength). If two control planes are used, and both are oriented perpendicular to mass flow, differences between discharge values over time can be used to evaluate natural attenuation capacity (e.g., reduction in discharge over time and space).

The US DOE project successfully demonstrated that historical and real-time hydraulic head and hexavalent chromium groundwater data can be uploaded, displayed, and 


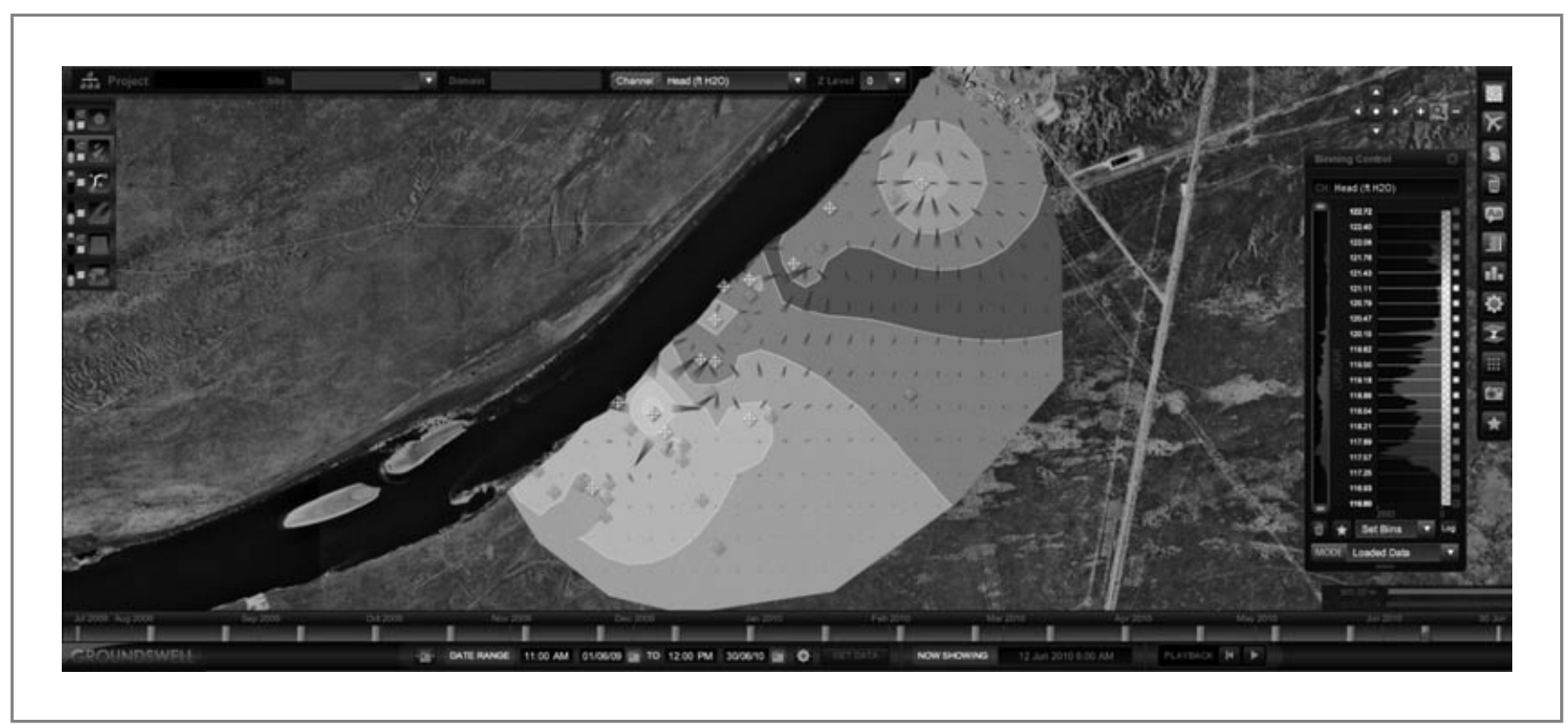

Exhibit 6. Head and gradient distributions, US DOE demonstration

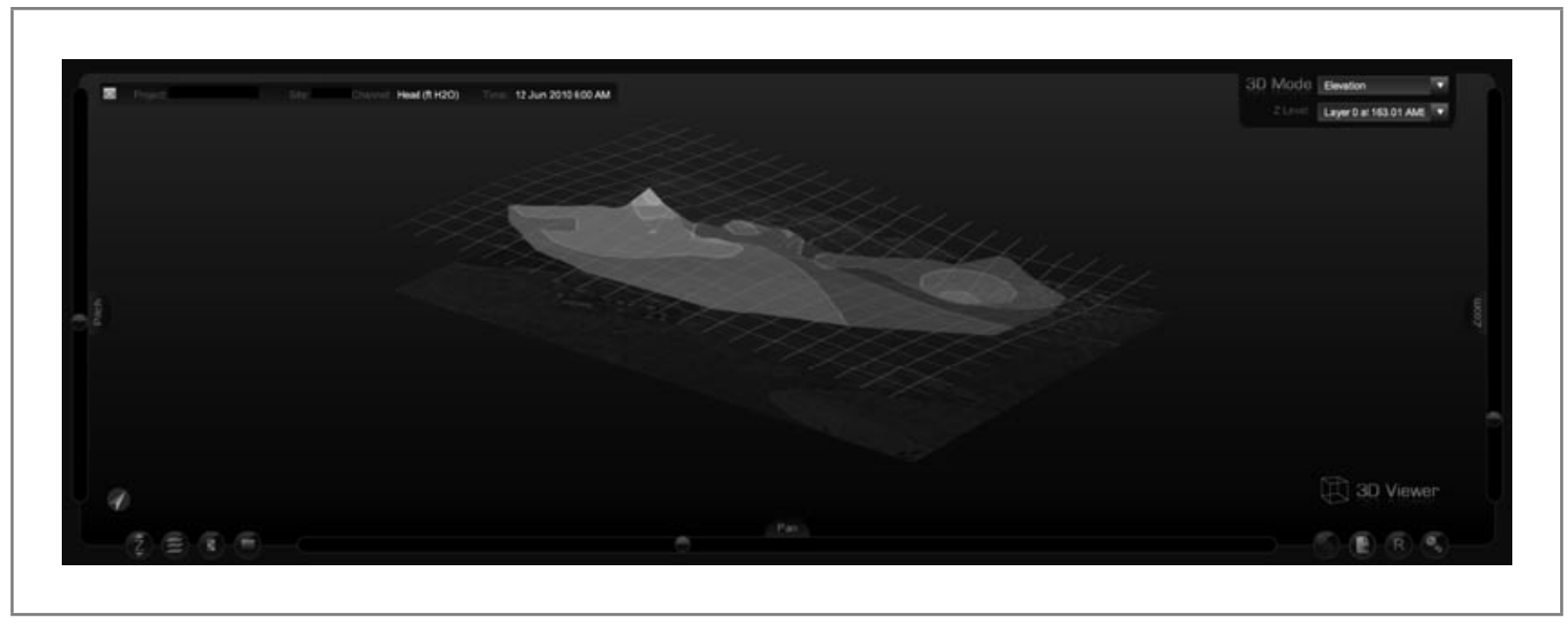

Exhibit 7. Three-dimensional head distributions, US DOE demonstration

analyzed using the web-based platform. Demonstrated features include time-series plots, histograms, contour maps (Exhibit 6), 3-D renderings (Exhibit 7), contaminant flux distributions, control plane mass discharge results (Exhibit 8), and animation loops. When evaluating mass discharge from the aquifer to the river, the platform was used to understand the cumulative discharge over time through a user-selected source control plane located along the shoreline within the hyporheic zone. Since flow can be varied, vectors and net discharge are displayed. The histogram at the base of Exhibit 8 depicts hexavalent chromium discharge in mass/time for each successive time step monitored. 


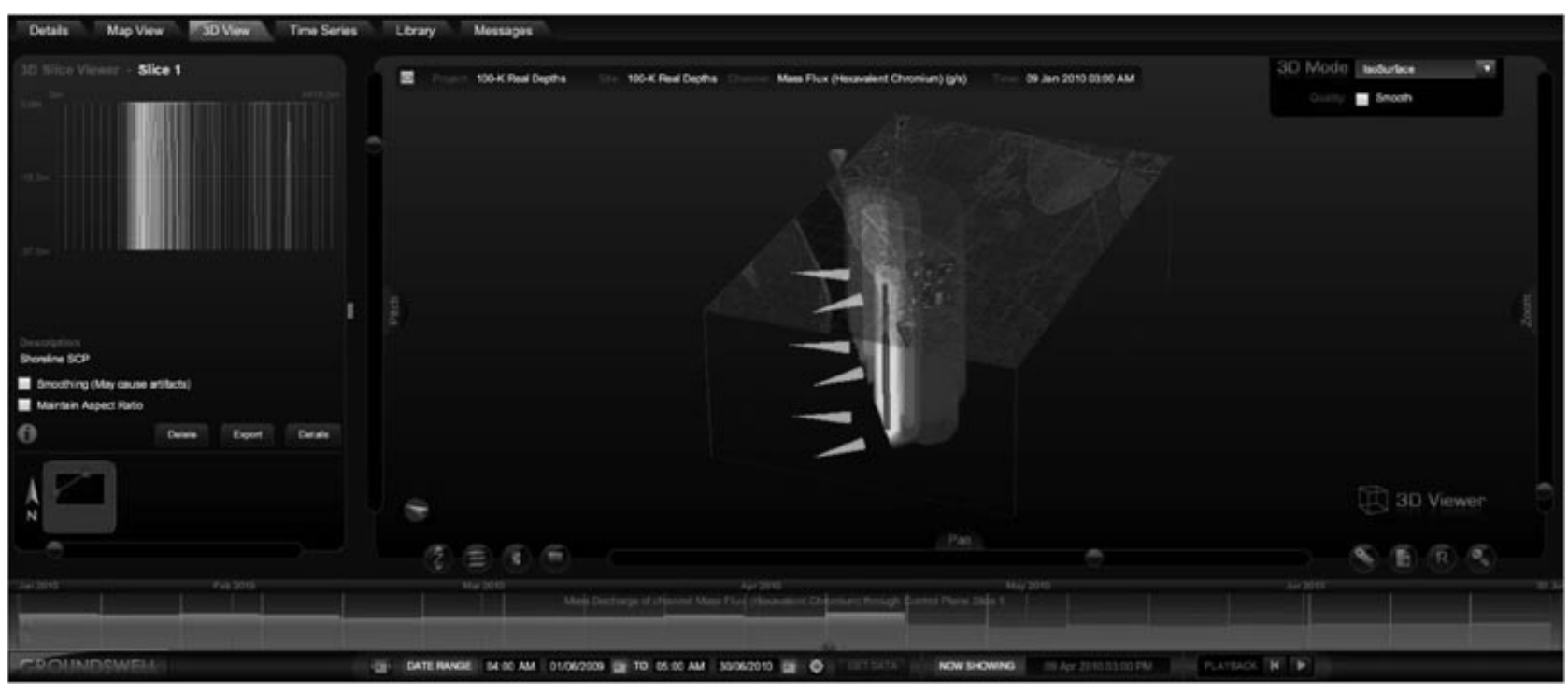

Exhibit 8. Mass discharge through control plane in the hyporheic zone, US DOE demonstration

The collaborating teams successfully demonstrated automation of project management tasks traditionally performed manually in support of report preparation, consensus-based analyses, and information dissemination in an on-demand web configuration. For the US DOE pilot demonstration, Waiora was customized to be able to handle the unique data set, which was composed of a partial well network within the operating units and included nonsimultaneous hexavalent chromium data with concentrations varying nearly two orders of magnitude. Discharge was observed to vary over time and space - most likely due to the hydraulic influences resulting from surface-water dam releases up river from the contaminant release sites.

All data transmittal and visualization objectives for both the US EPA and US DOE projects were achieved. The following features and analyses were demonstrated:

- project management (e.g., graphics generation, file repository, consensus based analyses, etc.);

- geospatial and temporal renderings;

- time-series analyses;

- interpolation of combined sensor and static data;

- combined contouring and time-series displays;

- 3-D image generation;

- time-stamped playback loops (2-D and 3-D);

- display and export of data for model calibration; and

- instant multivariate analyses for selected time ranges:

- velocity distribution display and tracking (see Darcy options),

- flux distribution display and tracking, and

- flux-based remediation performance assessment via discharge monitoring through a user-selected transect. 
Of most importance, mass discharge through a control plane was monitored and visualized in an automated web-based configuration. This approach can be used to evaluate historical trends, to track contaminant exchanges between groundwater and surface water in the hyporheic zone, and to establish and monitor remediation performance metrics and compliance strategies. Understanding source strength and mass discharge changes upgradient of the hyporheic zone can also be pursued by placing additional control planes in user-selected locations between the source zone and surface-water body. It is believed that mass flux and discharge monitoring over time could lead to superior compliance strategies, optimized remediation approaches, and new long-term monitoring guidance. This is supported by the release of an ITRC guidance on mass flux (ITRC, 2010) and the recent record of decision for Superfund Site 12A located in Tacoma, Washington, which includes mass discharge reduction targets as a remedial action objective and regulatory performance metric (US EPA, 2009).

Automated monitoring of changes in mass flux and discharge is consistent with Triad approaches, as it includes systematic planning, dynamic work plans (which include both spatial and temporal conceptualizations), and real-time measurements (i.e., sensor-based analyses). While green and sustainable remediation (GSR) programs primarily focus on resource footprints associated with the remediation processes, automating the required monitoring components can also yield formidable benefits. For instance, these types of automated remediation performance monitoring approaches are more time- and resource-efficient, as they can reduce energy and labor expenditures associated with data collection, sample collection, transportation, laboratory efforts, and report generation, and promote consensus-based analyses without travel requirements. Furthermore, reports can be paperless, and information is available in an on-demand centralized configuration.

\section{CONCLUSIONS}

This demonstration of on-demand, web-based hydrogeologic management applications emphasized long-term automated contaminant plume monitoring, mass flux-based remediation performance monitoring, evaluation of groundwater and surface-water interactions, and model validation. Of particular note, rapid visualization of site hydrogeochemical conditions and changes over time and space affords tremendous potential from a centralized project and program management perspective, and as a means to increase efficiency. Life-cycle costs and carbon footprints can be reduced due to the elimination of energy and labor expenditures associated with transportation, data collection, laboratory efforts, report generation, and information dissemination. While many types of sensors and automated field analytical systems are currently integrated, as more sensors become commercially available and accepted by the regulatory community, the number of sites where this approach can be utilized will increase.

\section{ACKNOWLEDGMENTS}

The authors are indebted to Dr. Scott Petersen (CH2MHILL Plateau Remediation Company), the US DOE's Richland Operations Office personnel, Clark Easter (TrifectaGIS), Justin Wood (TrifectaGIS), Cliff Frescura, Brian Kahl, and Jasmine Showers (Groundswell Technologies, Inc.) for their support throughout these
It is believed that mass flux and discharge monitoring over time could lead to superior compliance strategies, optimized remediation approaches, and new long-term monitoring guidance. 
demonstration efforts, as well as Stu Nagourney (New Jersey Department of Environmental Protection) and Dr. Michael Brody (US EPA) for their thoughtful insight and critical project coordination efforts in support of the ETV project. We also recognize the exceptional contributions by Amy Bowman (NJDEP), Chris Gardner (Battelle), Tom Moorman, Beth Douglas, and Jerry Hatfield (USDA/ARS), and acknowledge the essential support received from Kati Lentz and Rose Filoramo (students at the College of New Jersey).

\section{REFERENCES}

Barton A., Gardner C., Rhoda D., Dindal A., \& McKernan J. (2011). Instrumentation Northwest, Inc. Aquistar TempHion Smart Sensor and Dafalogger Nitrate-specific lon-selective Electrode for Groundwater Remediation. US Environmental Protection Agency, Washingtion, DC.

Interstate Technology \& Regulatory Council (ITRC). (2007). Triad implementation guide, SCM-3. Washington, DC: Interstate Technology \& Regulatory Council; Sampling, Characterization, and Monitoring Team.

Interstate Technology \& Regulatory Council (ITRC). (2010). Use and measurement of mass flux and mass discharge. Washington, DC: Interstate Technology \& Regulatory Council, Integrated DNAPL Site Strategy Team.

Kram, M. L., Beighley, R. E., Loaiciga, H. A., \& Nasser, K. (2010). Automated environmental monitoring, data visualization, and critical resource management. Seventh International Conference, Remediation of Chlorinated and Recalcitrant Compounds, Battelle, Monterey, California, May 24-27.

Kram, M. L., Robbins, G., Chau, J., \& Bagtzoglou, A. (2008). Detailed Hydraulic Assessment Using a High-Resolution Piezocone Coupled to the GeoVIS, Technical Report TR2291-ENV, Environmental Security Tech Cert. Program, NAVFAC, Port Hueneme, California.

Kram, M., Sirivithayapakorn, S., \& Beighley, R. E. (2005). GIS based real-time monitoring and reporting system, United States Patent No. 6,915,211. Washington, DC: US Patent Office.

Suthersan, S., Divine, C., Quinnan, J., \& Nichols, E. (2010). Flux-informed remediation decision making. Ground Water Monitoring \& Remediation, 30(1), 34-43.

US Department of Energy (US DOE). (2010). Hanford site groundwater monitoring and performance report for 2009, revision 1. DOE/RL-2010-11. Retrieved from http://www.hanford.gov/c.cfm/sgrp/GWRep09/ start.htm

US Environmental Protection Agency (US EPA). (2009). Amendment \#2 to the Record of Decision for the Commencement Bay-South Tacoma Channel Superfund Site, Operable Unit 1, Well 12A, EPA Region 10. Retrieved from http://yosemite.epa.gov/r10/CLEANUP.NSF/sites/CBSTC/\$FILE/cbstc_well12a rod_amend_2_102809.pdf

US Environmental Protection Agency (US EPA). (2010). Test/QA plan for verification of nitrate sensors for groundwater remediation monitoring, environmental technology verification test/quality assurance plan, Document no. 600/R-10/104. Washington, DC: Author.

Mark L. Kram, PhD, is the chief scientist for Groundswell Technologies, Inc., a group specializing in automated monitoring and modeling of environmental and homeland security sensor networks. He has over 27 years of 
experience using innovative environmental assessment techniques and has authored papers, national standards, articles, and book chapters on the subject.

Steve Airhart, RG, is the vice president of Freestone Environmental Services, Inc., in Richland, Washington. His focus is remedial investigation planning and implementation. Mr. Airhart received his BA in geology from the University of Montana. He is a registered geologist in Oregon and Washington.

Daniel Tyler, LHG, is the president of Freestone Environmental Services, Inc., in Richland, Washington. His focus is characterization, remediation, and protection of groundwater. Mr. Tyler received his BS in natural resources $\&$ environmental science from Purdue University and his MS in hydrology and water resources management from Colorado State University. He is a licensed hydrogeologist in Washington.

Amy Dindal, PMP, has been a project manager at Battelle for 8 years. Ms. Dindal has a bachelor's degree in chemistry and earned her project management certification in 2006.

Andrew Barton is a principal research scientist with Battelle and has more than 14 years of experience in designing soil and groundwater remediation systems and in managing various environmental engineering projects. Mr. Barton has a master's degree in hydrogeology and has performed extensive environmental and hydrogeological research, both in the field and through the use of computer modeling.

John L. McKernan, Sc.D., is a project officer for the US EPA Advanced Monitoring Systems (AMS) Center in Cincinnati, Ohio. His research interests include environmental monitoring, risk assessment, and engineering control technologies. He has been involved with the US EPA's AMS Center since 2008. Prior to transferring to the US EPA, he was a research scientist for the Centers for Disease Control and Prevention for 10 years. Dr. McKernan received his BA in physics from the University of North Carolina Wilmington, MSPH from the University of North Carolina at Chapel Hill, and $\mathrm{SCD}$ in environmental sciences from the University of Massachusetts Lowell.

Gregg Gustafson is the president of Instrumentation Northwest, Inc. (INW). in Kirkland, Washington. He received his BA in chemistry from the University of Washington. He is a patent holder in several environmental sensors and monitoring technology related to air and water resources. 